\title{
THE RELATIONSHIP BETWEEN SUKUK MARKET AND ECONOMIC GROWTH: PANEL CAUSALITY ANALYSIS
}

\section{DOI: 10.17261/Pressacademia.2020.1182}

JEFA- V.7-ISS.1-2020(7)-p.66-74

\section{Tunahan Avci}

Erciyes University, Faculty of Aviation and Space Sciences, Department of Aviation Management, Kayseri, Turkey. tnavci@erciyes.edu.tr, ORCID: 0000-0003-0434-5834

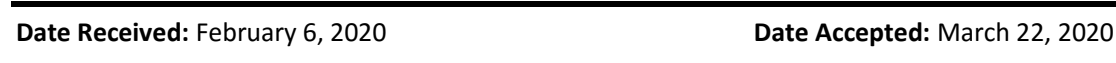

To cite this document

Avci, T., (2020). The relationship between Sukuk market and economic growth: panel causality analysis. Journal of Economics, Finance and Accounting (JEFA), V.7(1), p.66-74.

Permemant link to this document: $\underline{\text { http://doi.org/10.17261/Pressacademia.2020.1182 }}$

Copyright: Published by PressAcademia and limited licenced re-use rights only.

\section{ABSTRACT}

Purpose- The aim of this study is to examine the relationship between countries' Sukuk market development and economic growth. Panel VAR analysis was applied to investigate whether there is a realtionship between these two factors.

Methodology- In the analysis of the research, quarterly data of 2014Q1-2019Q2 period is used. Turkey, Kuwait, Malaysia, Pakistan, Saudi Arabian, Sudan, United Arab and Indonesia countries are included in the analysis. In the study, Dumitrescu Hurlin panel causality test was applied as a method. Sukuk and economic growth rates of the countries are used as a variable.

Findings- According to the findings obtained as a result of the analysis, a one-way causality relationship is observed from the economic growth to the Sukuk growth rate.

Conclusion- When the Sukuk and economic growth results are analyzed, there is no causality relationship from Sukuk growth rate to economic growth. However, a causality relationship has been identified from economic growth to Sukuk growth rate. When the economic growth variance decomposition results are analyzed, in the first period, the change in economic growth is fully explained by itself. When the Sukuk variance decomposition results are analyzed, $99.6 \%$ of the change in Sukuk in the first period is announced by itself.

Keywords: Economic growth, Sukuk, panel causality, response analysis.

JEL Codes: G19, G23, O16

\section{SUKUK PAZARI VE EKONOMIK BÜYÜME ARASINDAKi iLIŞKISI: PANEL NEDENSELLiK ANALizi}

\section{ÖZET}

Amaç- Bu çalışmanın amacı, ülkelerin Sukuk pazarı gelişimi ile ekonomik büyüme arasındaki ilişkisinin incelenmesidir. Bu iki faktör arasında bir ilişkinin olup olmadığı, Panel VAR analizi ile araştırılmaya çalışılmıştır.

Yöntem- Araştırmanın analizinde, 2014Q1-2019Q2 dönemi çeyreklik veriler kullanılmıştır. Çalışmada Türkiye, Kuwait, Malezya, Pakistan, Sadi Arabistan, Sudan, Birleşik Arap Emirliği ve Endonezya ülkeleri analize dahil edilmiştir. Çalışmada, Dumitrescu Hurlin panel nedensellik testi yöntem olarak uygulanmıştır. Ülkelerin Sukuk ve ekonomik büyüme oranları değişken olarak kullanılmıştır.

Bulgular- Yapılan analizler sonucunda elde edilen bulgulara göre, ekonomik büyümeden Sukuk büyüme oranına doğru tek yönlü bir nedensellik ilişkisi görülmektedir.

Sonuç- Sukuk ve ekonomik büyüme sonuçları incelendiğinde, Sukuk büyüme oranından ekonomik büyümeye doğru nedensellik ilişkisi görülmemiştir. Fakat, ekonomik büyümeden Sukuk büyüme oranına doğru bir nedensellik ilişkisi tespit edilmiştir. Ekonomik büyümenin varyans ayrıştırma sonuçları incelendiğinde, 1. dönemde ekonomik büyümedeki değişimin tamamı kendisi tarafından açıklanmaktadır. Sukuk'un varyans ayrıştırma sonuçları incelendiğinde ise, 1. dönemde Sukuk'daki değişimin \%99,6'sı kendisi tarafından açıklanmaktadır.

Anahtar Kelimeler: Ekonomik büyüme, Sukuk, panel nedensellik, tepki analizi JEL Kodları: G19, G23, O16 


\section{GiRiş}

Son yıllarda İslami finansın en dinamik ürünlerinden biri olan Sukuk, günümüzde küresel finansal sistemin önemli bir parçası haline gelmektedir. Said and Grassa (2013), Sukuk pazarının gelecek yıllarda dünya çapında güçlü bir büyüme potansiyeline sahip olacağını belirtmişlerdir.

Müslüman ülkelerdeki ihraççıların ve yatırımcıların İslami tercihlerine uygun alternatif bir ürün olan Sukuk, dünyanın pek çok yerinde ihraç edilmektedir. Başlangıçta, faizsiz işlem yapmak isteyenlerin finansman ve yatırım ihtiyaçları için ortaya çıksa da pek çok Müslüman ve gayrimüslim ülkelerde, hükümetler ve şirketler tarafından ekonomik ve sosyal projelerin finanse edilmesinde likidite aracı olarak kullanılmaktadır. Sukuk ihracıyla birlikte ülkelerin mal ve hizmet üretimi artabilecek, işsizliği ise azalabilecektir. Dolayısıyla, Sukuk pazarı ekonomik kalkınmada kilit bir rol oynayabilir ve ülkelerin gayri safi yurtiçi hasılalarını (GSYIH) destekleyebilir.

Sukuk'un ticari faaliyetlerin finanse edilmesi veya maddi varlıkların üretilmesi için tahsis edilen hem tahvil hem de hisse senedi benzeri özellikleri taşıyan yatırım sertifikaları olduğunu belirtmiştir (Godlewski vd., 2013; Al-raeai vd., 2018: 334). İslami tahvil olarak bilinen Sukuk, İslami yatırım sertifikaları olarak tanımlanabilmektedir (Smaoui ve Ghouma, 2019: 3). Sukuk, varlığa dayalı şekilde ihraç edilen çeşitli türleri olan İslami finansal enstrümandır. Bu varlık, dini bakımdan duyarlılı̆ı yüksek yatırımcılar ve finansal kuruluşlar tarafından genel olarak tercih edilmektedir. Sukuk ihraç eden kuruluşlar sermaye temin etmekte, bu varlığı satın alanlar ise dönemsel getiri elde etmekte ve vade sonunda kar paylarını almaktadırlar. İslami açıdan finansal piyasaları gelişmiş ülkeler, uluslararası alandaki yatırımcıları finansal piyasalarına çekmekte böylece reel sektörün gelişmesini sağlamaktadırlar (içellioğlu, 2019: 44).

Sukuk kendine has olarak bazı özelliklere sahiptir. Bunlar; *islam hukukuna göre düzenlenir. *Faizli getiriler yerine kira geliri ve kâr payı söz konusudur. *Belirsizliğin fazla olduğu işlemlerden kaçınılır. * Borç senedi değildir. *Anapara ve kazanç, ihraççı tarafından garanti edilmez (Yılmaz, 2014).

Ekonomik büyüme, ülkelerin refah düzeyindeki artışı ve yaşam standartlarında iyileşme sağlanabilmesi için önem arz etmektedir. Ülkelerin refah düzeyleri, bireylerin elde ettikleri gelirler ile talep ettikleri hizmet ve ürünleri karşılayabilme seviyelerini göstermektedir. Ekonomik büyüme, reel milli gelirin uzun dönemde artış göstermesidir. Bu artış ise, ülkedeki hizmet ve malların üretim miktarındaki yükselme olarak kabul edilmektedir (Şeker, 2018: 12).

Bu çerçevede, bu çalışma aşağıdaki soruların cevabını aramaktadır: Araştırmaya konu olan ülkelerin (Türkiye, Kuwait, Malezya, Pakistan, Sudi Arabistan, Sudan, Birleşik Arap Emirliği ve Endonezya) ekonomik büyümesi ile Sukuk gelişimi arasında nedensellik ilişkilisi var mı? Dönemler itibari ile ülkelerin ekonomik büyümeleri, Sukuk pazarını pozitif etkilemekte mi? Dönemler itibari ile ülkelerin Sukuk gelişimi, ekonomik büyümeyi pozitif etkilemekte mi? Şoklar, ekonomik büyüme ve Sukuk üzerinde ne kadar etkili?

Yapılan çalışmada ülkelerin Sukuk pazarı gelişimi ile ekonomik büyümeleri arasındaki ilişkisinin incelenmesi amaçlanmaktadır. Araştırmanın analizinde, 2013-2018 dönemi çeyreklik veriler ile panel nedensellik analizi yapılmaktadır. Sukuk pazarı gelişiminin göstergesi olarak Sukuk büyüme oranı, ekonomik büyümenin göstergesi olarakta gayri safi yurtiçi hasılanın büyüme oranı kullanılmaktadır.

Çalışmanın ilerleyen bölümlerinde öncelikle Sukuk pazarı gelişimi ile ekonomik büyüme arasındaki ilişkiyi araştıran çalışmaların literatür taramasına yer verilmiştir. Ardından yöntem ve veriler açıklanmıştır. Uygulama bölümü yapılan analiz çalışmalarını içermektedir. Son bölümde ise analiz sonuçlarına ilişkin değerlendirme ve öneriler sunulmuştur.

\section{LITERATÜR TARAMASI}

Son yıllarda İslami finansın önemli ürünlerinden biri olan Sukuk, çeşitli projelerin (ekonomik, sosyal, altyapı vb.) finansmanında yaygın olarak kullanılmaktadır. Küresel finansal sistem içerisinde yaygın olarak kullanılan bu ürünün, ekonomilerin kalkınmasına katkı sağladığı düşünülmektedir. Dolayısıyla yapılan çalışmada, ülkelerin Sukuk pazarı gelişimi ile ekonomik büyüme arasındaki ilişkinin incelenmesi amaçlanmıştır. Bu amaç doğrultusunda bu kısımda Sukuk pazarı ile ekonomik kalkınma ilişkisini araştıran çalışmaların literatür incelemesine yer verilmiştir.

Ahmad ve Radzi (2011), Malezya' daki ekonomik koşulların Sukuk ihracı üzerindeki etkilerini araştırmışlardır. Sonuç olarak, gayri safi yurtiçi hasılanın Malezya'daki Sukuk ihracının belirleyici faktörlerinden olduğunu tespit etmişlerdir.

Said ve Grassa (2013) tarafından yapılan araştırmada ekonomik büyümenin Sukuk pazarının gelişimini olumlu yönde etkilediğini ortaya koymuşlardır. 
Khoutem (2014) çalışmasında İslami bankaların Sukuk pazarı ile olan ilişkisini, Tunus'un ekonomik büyümesine katkı sağlayıp sağlamadığını araştırmıştır. Sonuç olarak, İslam bankaları ile Sukuk pazarları arasındaki ilişkilerin, ekonomik büyüme üzerinde kilit bir rol oynayabileceğini belirtmiştir.

Echchabi vd. (2016), Suudi Arabistan'daki Sukuk ihracının ekonomik büyüme üzerinde bir etkisinin olmadığını tespit etmek için granger nedensellik analizinin uygulamışlardır. Sonuç olarak bir etkinin olmadığı tespit edilmiştir.

Saleem, Fakhfekh ve Hachicha (2016) Sukuk ìhracı ile ekonomik büyüme ilişkisini incelemişlerdir. Bulgulara göre, Sukuk ihracıyla ekonomik büyüme arasında güçlü bir ilişki olduğunu ortaya koymuşlardır.

Echchabi vd. (2016) çalışmalarında 17 ülkenin Sukuk ihracının, ekonomik büyüme ve gelişme üzerindeki olası etkisini araştırmışlardır. Sonuçlara göre, Sukuk ihracının gayri safi yurt içi hasıla üzerinde etkili olduğunu tespit etmişlerdir.

Dimitris vd. (2016) ve Naifar vd. (2017), Sukuk'un küresel şoklara maruz kalmadığını ya da finansal kriz sırasında bulaşma risklerine maruz kalmadığını belirtmişlerdir. Yine, Sukuk'un uluslararası yatırımcılara portföy çeşitliliği için yol gösterebileceği belirtmişlerdir.

Smaoui ve Nechi (2017), Sukuk pazar gelişiminin ekonomik büyüme üzerindeki etkisini analiz etmişlerdir. Çalışmalarında, Sukuk pazar gelişiminin ekonomik büyümeye katkı sağladığına dair kanıtlar sunmuşlardır. Bulgular, Sukuk pazarının gelişiminin ekonomik büyümeyi olumlu yönde desteklediğini göstermektedir.

Malikov (2017) çalışmasında, Sukuk'un Malezya ve Sudi Arabistan ülkelerinin ekonomik büyümeleri üzerindeki etkisini araştırmıştır. Sukuk ihraçlarından sonra Malezya ve Sudi Arabistan ekonomileri üzerinde önemli iyileşmelerin görüldüğünü belirtmiştir.

Sari vd. (2018) çalışmalarında kurumsal Sukuk'un ekonomik büyüme üzerindeki kısa ve uzun vadeli etkilerini tespit etmeye çalışmışlardır. Sonuç olarak, kısa ve uzun vadede Sukuk'un ekonomik büyüme üzerinde önemli bir etkisinin olduğunu tespit etmişlerdir.

Muharam vd. (2019) Malezya ve Endonezya ülkelerinin yer aldığı çalışmalarında, Sukuk piyasası gelişimi ile ekonomik büyüme arasındaki ilişkiyi incelemişlerdir. Bulgulara göre, Endonezya'da ekonomik büyüme ve Sukuk pazarının gelişimi arasında çift yönlü bir nedensellik, Malezya'da ise ekonomik büyüme ile Sukuk piyasası gelişimi arasında tek yönde nedensellik ilişkisi ortaya koymuşlardır.

Sukuk ve ekonomik büyüme ilişkisini araştıran çalışmaların 2011 yılından sonra artmaya başladığı görülmektedir. Literatür taraması genel olarak değerlendirildiğinde, araştırmacıların çoğu Sukuk ile ekonomik büyüme arasında bir ilişkinin olabileceğini ortaya koymuşlardır.

\section{YÖNTEM VE VERILER}

Çalışmada, ülkelerin Sukuk pazarı gelişimi ile ekonomik büyümeleri arasındaki ilişki Panel VAR analizi ile incelenmektedir. Bunun için değişkenler arasındaki ilişkinin analiz edilmesinde Dumitrescu Hurlin panel nedensellik testi kullanılmaktadır. Yapılan çalışmada değişken olarak, ülkelerin çeyreklik bazdaki büyüme oranları (GDP) ve Sukuk büyüme oranları alınmıştır.

Granger nedensellik testi için heterojenliğin dikkate alınmasına imkân tanıyan Dumitrescu Hurlin (2012) panel nedensellik analiz testi birimler arasındaki bireysel wald istatistikleri ortalamasını esas almaktadır. Herhangi bir bireyde veya ülkede var olan bir ilişkinin diğer bireylerde veya ülkelerde de ortaya çıkması olası durumdur. Yatay kesitsel bilginin kullanımı heterojenliğin dikkate alınmasını gerektirmektedir. Bu sebeple Dumitrescu-Hurlin, heterojen paneller için nedensellik testi önermesinde bulunmuşlardır (Ülgen ve Özalp, 2017: 228).

Dumitrescu-Hurlin panel nedensellik testinde $X$ ve $Y, N$ sayıda birim için $T$ dönem boyunca gözlemlenen iki durağan süreci ifade ettiğinde, t zamanında her bir birim (i) için, (1) numaralı eşitlikteki doğrusal heterojen modelini esas alır (Alper ve Oransay, 2015: 80).

$Y_{i, t}=\propto_{i}+\sum_{k=1}^{K} y_{i}^{k} Y_{i, t-k}+\sum_{k=1}^{K} \beta_{i}^{k} X_{i, t-k}+\varepsilon_{i, t}$

Burada $K$, optimum gecikmeyi ifade etmektedir. Testin boş hipotezi, bütün yatay kesitlerde ' $X$ 'ten $Y$ 'ye nedensellik ilişkisi yoktur" şeklindedir.

Analizde kullanılan Sukuk ve ekonomik büyüme değişkenlerinin verileri, grafik 1 ve grafik 2'de yer almaktadır. 


\section{Grafik 1: Dönemler İtibari Sukuk Büyüme Oranları}

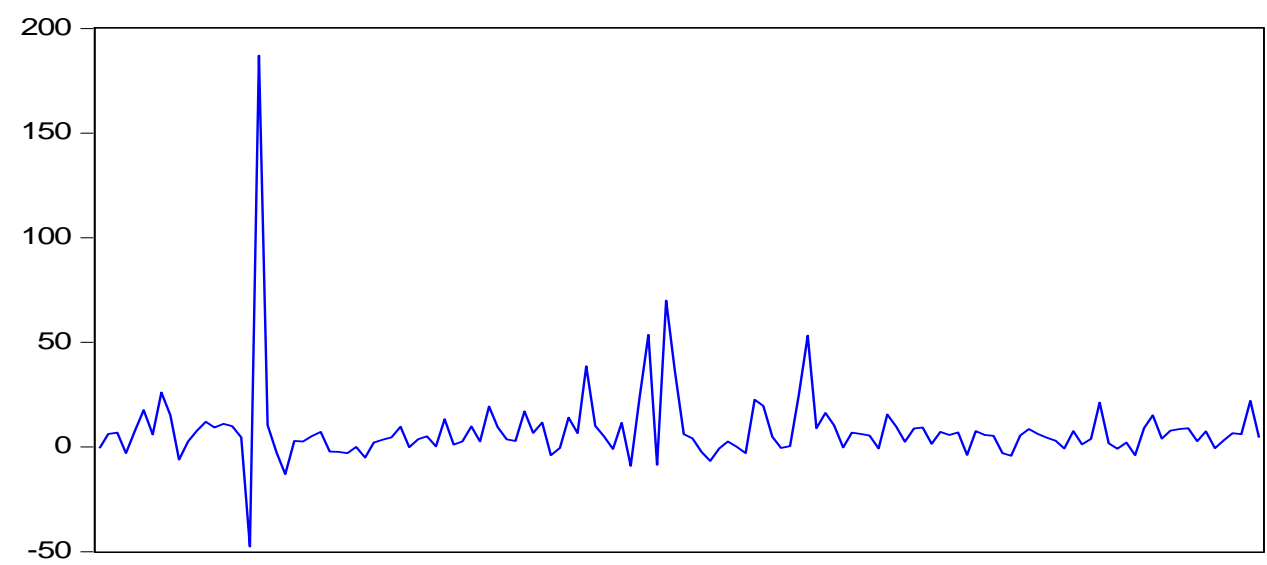

Grafik 2: Dönemler İtibari Ekonomik Büyüme Oranları

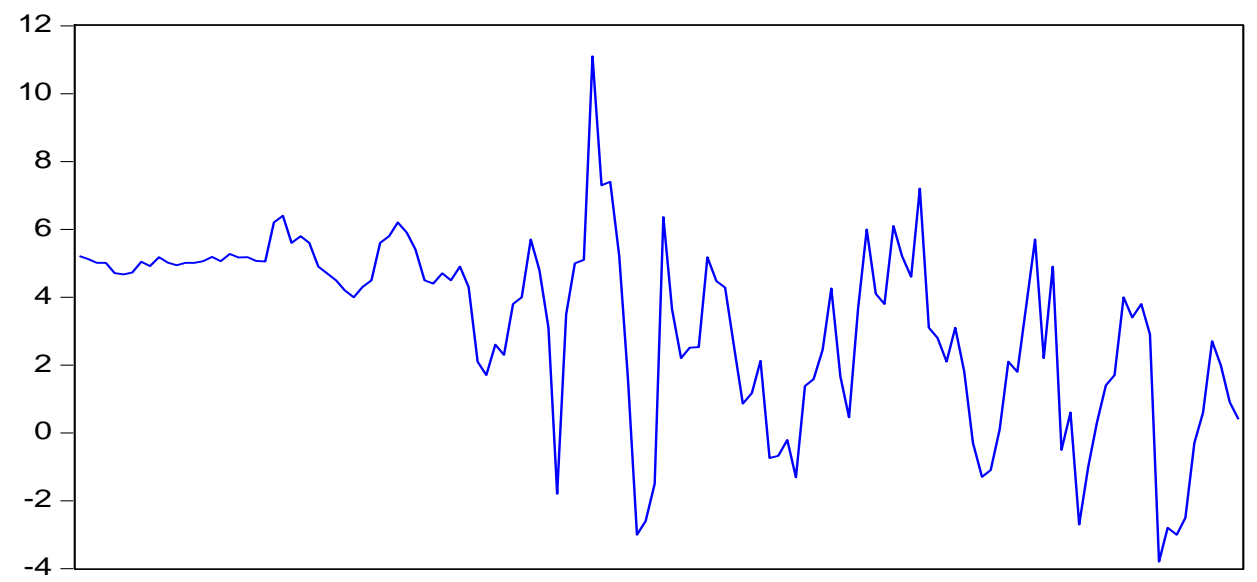

Analizinde dahil edilen ülkelerin (Türkiye, Kuwait, Malezya, Pakistan, Sudi Arabistan, Sudan, Birleşik Arap Emirliği ve Endonezya) 2014Q1-2019Q2 dönemi çeyreklik verileri IFSB (Islamic Financial Services Board) web sitesinden ve ülkelerin merkez bankalarına ait web sitelerinden alınmıştır. Analizin yapılabilmesi için EViews 9 programından yararlanılmıştır.

\section{ANALIZ SONUÇLARI}

Bu bölümde, ülkelerin Sukuk pazarı gelişimi ile ekonomik büyümeleri arasındaki ilişki araştııılmıştır. Bu bağlamda analizde, 2014Q1-2019Q2 dönemi çeyreklik verileri ile Dumitrescu Hurlin panel nedensellik testi yapılmıştır.

Yapılan analizde, değişkenlerin durağan olup olmadıklarına bakıldıktan sonra karakteristik polinom ters köklerine, geçikme uzunluklarına, Pairwise Dumitrescu Hurlin panel nedensellik test sonuçlarına, etki tepki fonksiyonları analiz sonuçlarına ve son olarak varyans ayrıştırması sonuçlarına yer verilmiştir.

Tablo 1, değişkenlerin farklı metotlarda tespit edilen düzey seviyesindeki durağanlık sonuçlarını göstermektedir.

Zaman serilerinde olduğu gibi, Panel veri modellerinde de sahte regresyon sorunuyla karşılaşmamak amacıyla değişkenlerin durağan olup olmadıklarının bilinmesi gerekmektedir (Şahbaz vd. 2014: 53; Sarıkovanlık vd.:2019:111). 
Tablo 1: Çeşitli Metotlara Göre Durağanlık Testi

\begin{tabular}{lllll}
\hline \hline Değişkenler & LLC & IPS & ADF & PP \\
\hline \hline Sukuk Büyüme & 0.0000 & 0.0000 & 0.0000 & 0.0000 \\
\hline \hline Ekonomik Büyüme & 0.0384 & 0.0005 & 0.0021 & 0.0426 \\
\hline \hline
\end{tabular}

Tablo 1'de, Levin, Lin \& Chu, Im, Pesaran and Shin W-stat, ADF- Fisher Chi-square, PP- Fisher Chi-square birim kök testleri sonuçlarına göre, Sukuk büyüme serisinin $\% 1$ anlamlılık seviyesinde, ekonomik büyüme serisinin ise $\% 1$ ve $\% 5$ anlamlılık seviyelerinde durağan olduğu görülmektedir.

\section{Şekil 1: Karakteristik Polinom Ters Kökleri}

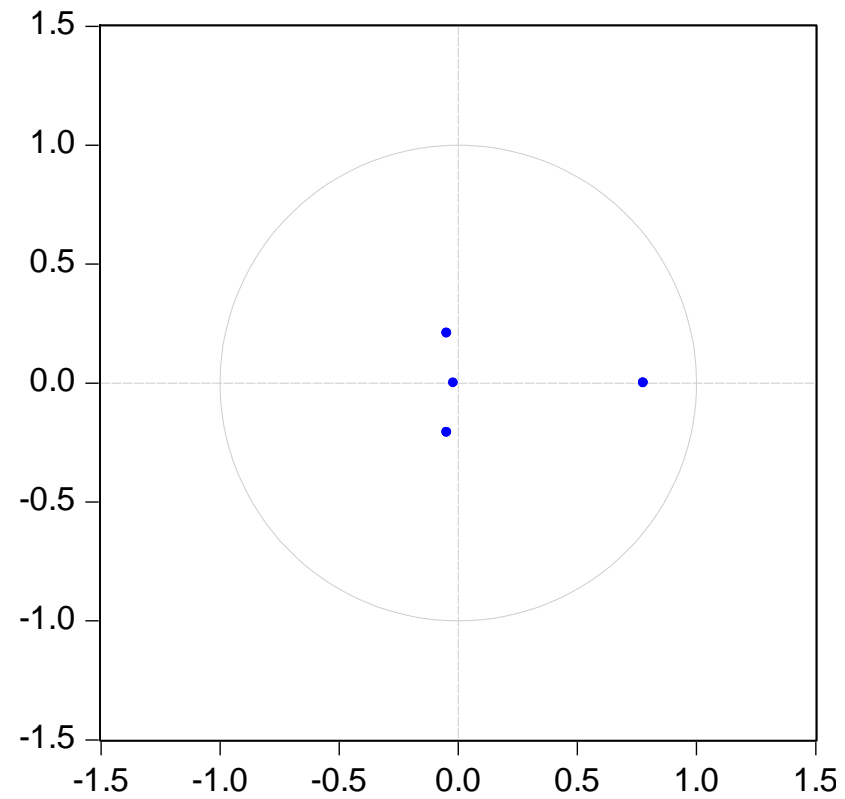

Karakteristik polinomun bütün ters kökleri birim çember içinde yer alması, modelin bütün olarak durağan olduğunu göstermektedir (Şimşek ve Yiğit, 2017:126). Dolayısıyla, yapılan çalışmada model bir bütün olarak değerlendirildiğinde modelin durağan olduğu görülmektedir.

Tablo 2' de Pairwise Dumitrescu Hurlin panel nedensellik testi sonuçlarına yer verilmiştir.

Tablo 2: Pairwise Dumitrescu Hurlin Panel Nedensellik Testi Sonuçları

\begin{tabular}{lccc}
\hline \hline Sıfır Hipotezi & W-Stat. & Zbar-Stat. & Prob. \\
\hline \hline Sukuk, homojen olarak büyümenin nedeni değildir & 3.66111 & -0.93451 & 0.3500 \\
Büyüme, homojen bir şekilde Sukuk'un nedeni değildir & 20.0963 & 3.06636 & $0.0022^{* *}$ \\
\hline \hline
\end{tabular}

*Modelde gecikme uzunluğu “5” alınmıştır.

**\%1 anlamlılık seviyesinde

Tablo 2'deki Sukuk ve ekonomik büyüme sonuçları incelendiğinde, Sukuk büyüme oranından ekonomik büyümeye doğru nedensellik ilişkisi görülmemiştir. Fakat, ekonomik büyümeden Sukuk büyüme oranına doğru bir nedensellik ilişkisi tespit edilmiştir. Dolayısıyla analiz sonuçları, ekonomik büyümeden Sukuk büyüme oranına doğru tek yönde nedensellik ilişkinin olduğunu göstermektedir. Diğer bir ifade ile ekonomik büyümenin Sukuk'u büyüten bir faktör olduğunu söyleyebiliriz.

Grafik 3 ve grafik 4 çeyreklik bazda 10. döneme kadar, değişkenlerin etki tepki fonksiyonlarını vermektedir.

Grafik 3, analizde kullanılan ülkelerin ekonomik büyümelerinin Sukuk’a olan tepkisini göstermektedir. 


\section{Grafik 3: Etki Tepki Fonksiyonları}

\section{Response of GDP to Sukuk}

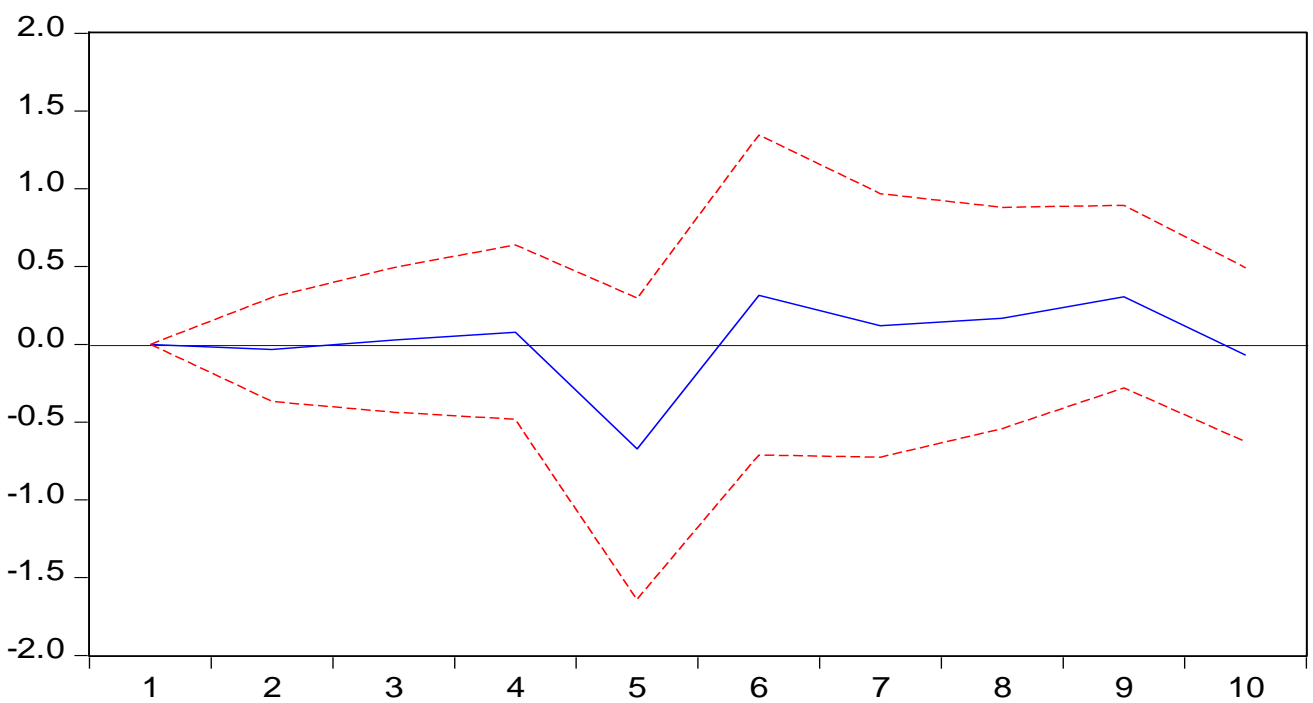

Değişkenlerden birine etki eden bir şokun diğer değişkenler üzerindeki etkisini de göstermesi açısından yaygın bir biçimde kullanılan Cholesky bir birimlik standart hatanın etkisine karşııı değişkenlerin vermiş oldukları tepkilere gözlemler (Akkuş, 2019: 65).

Grafik 3'te, Sukuk'daki bir standart hatalık şoka ekonomik büyüme ilk 3 dönemde neredeyse tepki vermemekte, 5 . dönemde negatif tepki vermekte daha sonra 9. döneme kadar pozitif tepki vermektedir. Genel olarak bakıldığında ekonomik büyümenin pozitif tepki verdiği görülmektedir.

Grafik 4, analizde kullanılan ülkelerin Sukuk artışlarının ekonomik büyümeye tepkisini göstermektedir.

\section{Grafik 4: Etki Tepki Fonksiyonları}

\section{Response of Sukuk to GDP}

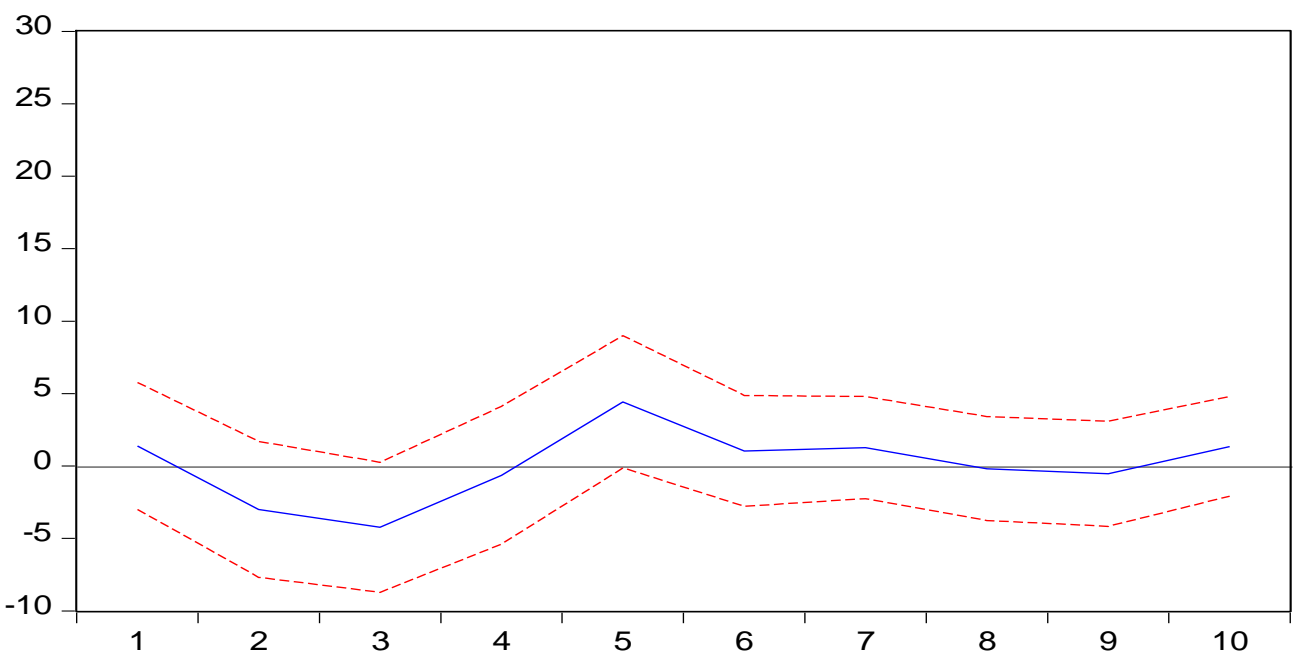

Grafik 4'te ekonomik büyümedeki bir standart hatalık şoka Sukuk'un tepkisi ilk 4 dönemde negatif daha sonra 8. döneme kadar pozitif tepki ortaya çıkmakta ve devamında bu pozitif tepkinin azaldığı görülmektedir.

Tablo 3, çeyreklik bazda ilk 10 dönemdeki şokların GDP'ye etkilerinin varyans ayrıştırması sonuçlarını göstermektedir. 
Tablo 3: Şokların GDP'ye Etkilerinin Varyans Ayrıştırması

\begin{tabular}{cccc}
\hline \hline Dönem & S.E. & G & Sukuk \\
\hline \hline 1 & 1.608419 & 100.0000 & 0.000000 \\
2 & 2.190379 & 99.97735 & 0.022648 \\
3 & 2.610483 & 99.97308 & 0.026921 \\
4 & 2.859880 & 99.90276 & 0.097240 \\
5 & 2.956976 & 94.73842 & 5.261578 \\
6 & 2.985624 & 93.72050 & 6.279501 \\
7 & 2.990046 & 93.57730 & 6.422700 \\
8 & 2.994919 & 93.28471 & 6.715288 \\
9 & 3.010489 & 92.32231 & 7.677687 \\
10 & 3.013744 & 92.28652 & 7.713479 \\
\hline \hline
\end{tabular}

Nedensellik analizi, değişkenler arasındaki ilişkinin varlığını ve yönünü test etmesine rağmen, etkinin düzeyi varyans ayrıştırma analizi ile, değişkenin etkili bir araç olarak kullanılma düzeyi ise etki tepki analizi yardımıyla ölçülür. Varyans ayrıştırma analizi sonucunda elde edilecek tablolar yardımıyla modelde kullanılan her bir değişkende oluşacak değişimin yüzde kaçının diğer değişkenler ve değişkenin kendisi tarafından meydana geldiği açıklanmaktadır (Yıldız, 2019: 3430).

Tablo 3'te ekonomik büyüme varyans ayrıştırma sonuçları incelendiğinde, 1. dönemde ekonomik büyümedeki değişimin tamamı kendisi tarafından açıklanmaktadır. Illk 4 dönemde, ekonomik büyüme değişimi neredeyse Sukuk tarafından açıklanmamaktadır. Tablo 3'te 5 . döneme bakıldığında ekonomik büyümedeki değişimin \%5,2'lik kısmı Sukuk tarafından açıklanmakta ve bu etki giderek artmaktadır.

Tablo 4, çeyreklik bazda ilk 10 dönemdeki şokların Sukuk'a etkilerinin varyans ayrıştırması sonuçlarını göstermektedir.

Tablo 4: Şokların Sukuk'a Etkilerinin Varyans Ayrıştırması

\begin{tabular}{cccc}
\hline \hline Dönem & S.E. & G & Sukuk \\
\hline \hline 1 & 22.15246 & 0.388779 & 99.61122 \\
2 & 22.75021 & 2.111476 & 97.88852 \\
3 & 23.15092 & 5.387743 & 94.61226 \\
4 & 23.15999 & 5.460740 & 94.53926 \\
5 & 23.69320 & 8.699696 & 91.30030 \\
6 & 23.99626 & 8.668229 & 91.33177 \\
7 & 24.04838 & 8.905327 & 91.09467 \\
8 & 24.11731 & 8.860559 & 91.13944 \\
9 & 24.17452 & 8.868775 & 91.13122 \\
10 & 24.39995 & 9.011026 & 90.98897 \\
\hline \hline
\end{tabular}

Tablo 4'te Sukuk varyans ayrıştırma sonuçları incelendiğinde, 1. dönemde Sukuk'daki değişimin \%99,6'sı kendisi tarafından açıklanmaktadır. Tablo 4'te 2 . döneme bakıldığında Sukuk değişimin \%2,1'lik kısmı ekonomik büyüme tarafından açıklanmakta ve bu etki giderek artmakta son dönemde \%9,01 seviyesine ulaşmaktadır.

\section{SONUÇ}

Analizde, 2014Q1-2019Q2 dönemi çeyreklik veriler ve Dumitrescu Hurlin panel nedensellik testi kullanılmıştır. Yapılan araştırmaya, Sukuk piyasasında öncü olan Türkiye, Kuwait, Malezya, Pakistan, Sudi Arabistan, Sudan, Birleşik Arap Emirliği ve Endonezya ülkeleri dahil edilmiştir. 
Araştırmanın analizinde, değişkenlerin birim köklerine bakılmış ve birim kök içermediği tespit edilmiştir. Daha sonra sırasıyla karakteristik polinom ters kökleri, Pairwise Dumitrescu Hurlin panel nedensellik test sonuçları, etki tepki fonksiyonları analiz sonuçları son olarak varyans ayrıştırması sonuçları incelenmiştir.

Analizde değişkenlerin durağan oldukları belirlendikten sonra, karakteristik polinom ters köklerine göre bir bütün olarak modelin durağan olduğu görülmüştür. Panel nedensellik testi sonuçları incelendiğinde ekonomik büyümeden Sukuk büyüme oranına doğru tek yönde nedensellik ilişkisi görülmüştür.

Ekonomik büyüme varyans ayrıştırma sonuçları incelendiğinde, 4. dönemden sonra ekonomik büyümedeki değişim Sukuk tarafından gittikçe daha fazla açıklanmaktır. Sukuk varyans ayrıştırma sonuçlarına göre, 2 . dönemde Sukuk değişimin $\% 2,1^{\prime}$ lik kısmı ekonomik büyüme tarafından açıklanırken bu etki son dönemde $\% 9,01$ seviyesine ulaşmıştır.

Analiz bulgularına benzer olarak, Ahmad ve Radzi (2011), Said ve Grassa (2013), Saleem, Fakhfekh and Hachicha (2016) ve Muharam vd. (2019) ekonomik büyümenin, Sukuk'un nedeni olduğunu ortaya koymuşlardır. Yine bulgulara benzer olarak, Echchabi vd. (2016), Sukuk'un, ekonomik büyümenin nedeni olmadığını ortaya koymuşlardır.

Araştırmacılar, Sukuk ve ekonomik büyüme arsındaki ilişkiye farklı yöntemler ile inceleyebilirler. Ülkeler bazında tek tek Sukuk ve ekonomik büyüme ilişkisine bakılabilir. Aynı zamanda, Sukuk ve ekonomik büyüme değişkenlerinin anlamlılı̆ı ve etkisi araştırılabilir.

\section{KAYNAKLAR}

Ahmad, W.\& Radzi, R.M., (2011). Sustainability of Sukuk and conventional bond during financial crisis: Malaysian capital market. Glob. Econ. Financ. J. 4, 1-14.

Akkuş, Ö. (2019). Türkiye'de para talep fonksiyonu ve para politikası. Uluslararası Ekonomik Araştırmalar Dergisi, 5(3).

Alper, A., \& Oransay, G. (2015). Cari açık ve finansal gelişmişlik ilişkisinin panel nedensellik analizi ekseninde değerlendirilmesi. Uluslararası Ekonomi ve Yenilik Dergisi, 1(2), 73-85.

Al-Raeai, A. M., Zainol, Z., Rahim, A. K. B. A., \& Khilmy, A. (2018). The role of macroeconomic factors on Sukuk market development of GULF cooperation council (gcc) countries. International Journal of Economics and Financial Issues, 8(3), 333-339.

Khoutem, D. (2014). Islamic banks-Sukuk markets relationships and economic development: The case of the Tunisian post-revolution economy. Journal of Islamic Accounting and Business Research, 5(1), 47-60.

Dimitris, K., Naifar, N. \& Dimitrios, D., (2016). Islamic financial markets and global crises: contagion or decoupling? Econ. Model. 57, 36-46.

Dumitrescu, Elena-Ivona \& Hurlin, Christophe (2012). Testing for granger noncausality in heterogeneous panels. Economic Modelling, 29(4):1450-1460.

Echchabi, A., \& Idrıss, U. (2016). Does Sukuk financing promote economic growth? An emphasis on the major issuing countries. Türkiye islam iktisadı Dergisi, 3(2), 63-73.

Godlewski, C.J., Turk-Ariss, R. \& Weill, L. (2013), Sukuk vs. conventional bonds: A stock market perspective. Journal of Comparative Economics, 41(3), 745-761.

İçellioğlu, C. Ş. (2019). Bir sermaye piyasası aracı olarak Sukuk: S\&P Sukuk endeksi ve geleneksel tahvil endeksi üzerine bir uygulama. Bolu Abant İzet Baysal Üniversitesi Sosyal Bilimler Enstitüsü Dergisi, 19(1), 43-62.

Khoutem, D. B. J. (2014). Islamic banks-Sukuk markets relationships and economic development: The case of the Tunisian post-revolution economy. Journal of Islamic Accounting and Business Research, 5(1), 47-60.

Malikov, A. (2017). How do sovereign Sukuk ımpact on the economic growth of developing countries? An analysis of the ınfrastructure sector. In critical issues and challenges in Islamic economics and finance development (pp. 1-37). Palgrave Macmillan, Cham.

Muharam, H., Anwar, R. J., \& Robiyanto, R. (2019). Islamic stock market and sukuk market development, economic growth, and trade openness (the case of Indonesia and Malaysia). Business: Theory and Practice, 20, 196-207.

Naifar, N., Mroua, M. \& Bahloul, S., (2017). Do regional and global uncertainty factors affect differently the conventional bonds and sukuk? New evidence. Pac. Basin Financ. J. 41, 65-74.

Said, A. \& Grassa, R. (2013). The determinants of Sukuk market development: Does macroeconomic factors influence the construction of certain structure of Sukuk? Journal of Applied Finance \& Banking 3 (5): 251-267.

Saleem, M. B., Mohamed, F., \& Nejib, H. (2016). Is the relationship between financial development and economic growth monotonic? evidence from a sample of middle income countries. World Development. 
Sâri, N., Syamsurijal, A. K., \& Widiyanti, M. (2018). The impact of Islamic capital market development on economic growth: The case of Indonesia. Journal of Smart Economic Growth, 3(2), 21-30.

Sarıkovanlık, V., Koy, A., Akkaya, M., Yıldırım, H. H. \& Kantar, L. (2019). Finans biliminde ekonometri uygulamaları, Seçkin Yayıncılık, Ankara. Smaoui, H. \& Nechi, S., (2017). Does Sukuk market development spur economic growth? Res. Int. Bus. Financ. 41, $136-147$.

Smaoui, H., \& Ghouma, H. (2020). Sukuk market development and Islamic banks' capital ratios. Research in International Business and Finance, 51, 101064.

Şahbaz, A., Yanar, R., \& Adıgüzel, U. (2014). Ar-Ge harcamaları ve ileri teknoloji mal ihracatı ilişkisi: panel nedensellik analizi. Çukurova Üniversitesi Sosyal Bilimler Enstitüsü Dergisi, 23(1), 47-60.

Şeker, A. (2018). Teknolojik ürün ticareti ve ekonomik büyüme ilişkisi. Yalova Üniversitesi Sosyal Bilimler Enstitüsü, Doktora Tezi.

Şimşek, T., \& Yiğit, E. (2017). BRICT ülkelerinde yenilenebilir enerji tüketimi, petrol fiyatları, CO2 emisyonu, kentleşme ve ekonomik büyüme üzerine nedensellik analizi. Eskişehir Osmangazi Üniversitesi İktisadi ve İdari Bilimler Dergisi, 12(3), 117-136.

Ülgen, G., \& Özalp, L. F. A. (2017). Bir refah devleti analizi: Ekonomik ve sosyal sonuçlar. Siyasal Bilimler Dergisi, 5(2), $219-243$.

Yıldız, F. (2019). Türkiye ekonomisinde dış borç, ekonomik büyüme ve cari işlemler dengesi ilişkisinin analizi. MANAS Sosyal Araştırmalar Dergisi, 8(4), 3416-3438.

Yilmaz, E. (2014). Yeni bir finansal araç olarak Sukuk: Çeşitleri, Türkiye uygulaması ve vergilendirilmesi. Journal of Accounting \& Finance, (61). 